\title{
Performance evaluation of solar flat plate collector using different working fluids through computational fluid dynamics
}

\author{
Imran Nazir Unar ${ }^{1}$. Ghulamullah Maitlo ${ }^{2}$ Shoaib Ahmed ${ }^{2}$. Syed Saad Ali ${ }^{3}$. Abdul Qayoom Memon ${ }^{2}$. \\ Ghulam Abbas Kandhro ${ }^{4}$. Abdul Sattar Jatoi ${ }^{2}$
}

Received: 23 August 2019 / Accepted: 8 January 2020 / Published online: 14 January 2020

(c) Springer Nature Switzerland AG 2020

\begin{abstract}
The aim of this study involves establishing a three-dimensional computational fluid dynamic (3D-CFD) model of solar flat plate collector (SFPC) in order to investigate the effect of operating and geometric parameters on thermal efficiency. In this research work, commercial CFD code ANSYS FLUENT 14.0 version was used for the development of a model of solar plate collector. The single circular tube geometry was created using ANSYS DesignModeler 14.0 . The general continuity equation along with Navied-Stokes equations was solved for tracking motion of the working fluid. The general $k-\varepsilon$ turbulence modeling approach was used for solving the turbulence in the flow. Solar ray tracing was activated for calculating solar load in the model. The latitude and longitude of the Hyderabad region were inserted in the solar raytracing model for calculating solar intensity as per local conditions. Two fluids i.e., water and air were circulated with different flow rates in the developed model of SFPC. It was observed that water gave higher efficiency due to high density and thermal conductivity. The simulation results gathered revealed that the temperature of water and air was raised by almost $79^{\circ} \mathrm{C}$ and $73^{\circ} \mathrm{C}$ respectively.
\end{abstract}

Keywords Solar flat plate collector $\cdot$ CFD modeling $\cdot$ Solar ray tracing $\cdot$ Water $\cdot$ Air $\cdot$ Heating

\section{List of symbols}

3D Three dimensional

CFD Computational fluid dynamic

SFPC Solar flat plate collector

${ }^{\circ} \mathrm{C} \quad$ Centigrade

i.e. $\quad$ Id est

$\mathrm{SO}_{x} \quad$ Sulfur oxides

$\mathrm{NO}_{x} \quad$ Nitrogen oxides

$\% \quad$ Percent

ANN Artificial neural network

ANFIS Adaptive neuro-fuzzy interface system

GA Genetic algorithm

$\varepsilon \quad$ Emissivity

RTE Radiative transfer equation

$\begin{array}{ll}\text { DO } & \text { Discrete ordinate } \\ \sigma & \text { Stephan-Boltzmann constant } \\ \mathrm{W} / \mathrm{m}^{2} & \text { Watt per meter square } \\ \mathrm{K} & \text { Kelvin } \\ \mathrm{kg} / \mathrm{s} & \text { Kilogram per second } \\ \lambda & \text { Thermal conductivity } \mathrm{W} /\left(\mathrm{m}^{2} \mathrm{~K}\right) \\ \mathrm{T} & \text { Temperature } \\ \rho & \text { Optical reflectance } \\ \nabla & \text { Del, or nabla }\end{array}$

Ghulamullah Maitlo, metlo2696@yahoo.com | 'Department of Chemical Engineering, Mehran University of Engineering and Technology, Jamshoro, Sindh, Pakistan. ${ }^{2}$ Department of Chemical Engineering, Dawood University of Engineering and Technology, Karachi, Sindh, Pakistan. ${ }^{3}$ Department of Energy System Engineering, Mehran University of Engineering and Technology, Jamshoro, Sindh, Pakistan. ${ }^{4}$ Department of Basic Sciences, Mathematics and Humanities, Dawood University of Engineering and Technology, Karachi, Sindh, Pakistan.

SN Applied Sciences (2020) 2:209 | https://doi.org/10.1007/s42452-020-2005-z 


\section{Introduction}

The need for energy production and utilization is increasing tremendously throughout the world [50]. Because of the rapid increase in the world population, smart utilization of energy will help in minimizing financial and environmental problems faced by countries during the generation of energy. Currently, the contribution of fossil fuels in global energy production is more than $80 \%[43,53]$. The application of nonrenewable energy sources such as coal, gas, and oil produces higher amounts of environmental emissions including carbon dioxide, $\mathrm{SO}_{x^{\prime}} \mathrm{NO}_{x^{\prime}}$ particulate matter and other toxic gases. The emissions of harmful contaminants into the atmosphere lead to global warming, ozone depletion, eutrophication, acidification and health-related problems globally. Though the application of fossil fuels causes serious environmental glitches, the consumption of fossil resources is increasing by nearly $2 \%$ per year. Furthermore, to deal with issues related to the fossil fuels application for energy generation, the research is more focused on renewable energy options [15]. Renewable energy options are solar, wind, geothermal, tidal, and bioenergy [28]. Among renewable energy resources, solar energy is preferred due to low investment cost, efficient and clean energy source [26]. Furthermore, to fulfill the energy demand at a global level, more research and development is required in renewable energy conversion technologies $[23,44]$. Renewable energy is gathered from natural sources that can replenish within a short period $[4,5]$. Moreover, researchers are more focused on solar energy which is inexhaustible, freely available, and environmentally friendly $[2,6]$. The energy gathered from the sun can be used through three hightech conversion processes that include thermal, chemical and electrical [34]. Solar energy can be converted into mechanical energy like wind energy, hydro energy, and steam energy is converted into mechanical energy $[20,41]$. Solar energy is collected through a solar collector that is a special kind of heat exchanger $[3,57]$. The solar collector converts solar radiation into thermal energy which is used for thermal applications and solar radiation can also be converted into electrical energy directly as in photovoltaic application [7]. During thermal applications, the radiant energy is absorbed by the solar devices and transferred into the heat [12]. Thus the heat produced through solar devices is used for the heating of working fluid [13].

Solar flat plate collectors recently developed are widely used for the domestic as well as for commercial purposes such as for water heating and space heating $[35,46]$. Recently developed solar devices are easy to fabricate, install, maintain and least expensive. Solar radiant energy collectors (flat plate) are classified into two types in first type liquid is the heat transfer fluid and in the second type of flat plate, a collector is that in which air is used as a heat transfer fluid [49]. In 1958 Hottel \& Woertz worked on flat plate solar collectors [30]. Later on, research was done by other researchers to establish and investigate the thermal efficiency of solar flat plate collectors. The configuration of solar plate collector mainly comprises of aluminum rails, insulators, risers, header pipes, absorber and back sheets $[1,47]$. The aluminum is used for the fabrication of absorber and welded with the riser in order to transfer heat to working fluid. Different researchers have used artificial intelligence for the enhancement of efficiency of solar collectors. Kalogirou [56] observed that artificial neural network (ANN) and genetic algorithm are reliable for the prediction of solar collector's efficiency. Mohammad Zadeh et al. [39] assessed the thermal efficiency of parabolic high trough collector and performed hybrid optimization using Nanofluid. The procedure adopted by Mohammad Zadeh et al. [39] contained sequential quadratic programming and genetic algorithm for the optimization of solar collector efficiency.

Bagheri et al. [9] worked on solar dryers in order to estimate performance efficiency using neuro-fuzzy interface system (ANFIS) modeling approach. As per their study, ANFIS predicts accurately the performance of forced convection dryers. Shahmaleki et al. [48] worked on the enhancement of power efficiency of the solar power plant. They used two different analytical approaches to predict solar power plant efficiency. During the optimization of the solar power plant applied ANFIS and GA algorithms, suggested that both algorithms were reliable in the optimization of a solar power plant. Hamdan et al. [25] investigated solar flat plate collector optimization using ANN algorithms which is the most promising and efficient algorithm. As per their findings, ANN predicts accurately the mean temperature at all solar collector surfaces.

Dikmen et al. [17] worked on the modeling of an evacuated tube through the application of ANFIS and ANN algorithms. The results gathered in their study were reliable and were in good agreement with the results collected from experimental studies done by different researches. Numerous other studies revealed that the arterial neural network modeling is efficient, reliable in forecasting the solar radiations. ANN approach is simple and better than other forecasting methods [11]. The performance prediction of solar thermal energy was done by numerous researchers using artificial neural network approach including solar water heaters used in domestic applications [51], solar water heaters used on commercial scale accomplishments [55], solar collectors [32] and 
photovoltaic cells [33]. The feed-forward neural network comprising of the multilayer is the most appropriate and precise in the prediction of heat collection efficiency.

Most of the researchers have worked on ANN, GA, and ANFIS in their studies whereas scant literature is available on the computational fluid dynamic simulation of solar flat plate collectors and dryers. Generally, the Computational fluid dynamic (CFD) tool was related to solving the problems for non-linear partial differential equations that were described as the behaviors and phenomena of the fluid dynamics. Basically, the governing equations were derived from the mass conservation, momentum conservation, and energy conservation equations to solve any problems related to engineering in mass and heat transfer $[37,38]$.

Zima and Dziewa [59, 60], analyzed the effects of inertia on glass cover, such as insulation, and finding air gaps by using a one-dimensional process $5 n$-node method. Therefore in this study, CFD simulation is done to investigate and predict the thermal efficiency of solar flat plate collectors. The validity of the computational results gathered in this study is done through the comparison of experimental studies and simulation studies done by other researchers. Furthermore, the prime objective of this simulation study is to suggest an appropriate modeling approach that is easy, fast, precise and accurate in the prediction of results. In the present research, an attempt is made to study the performance of solar flat plate collector (SFPC) with Pakistani geological coordinates. CFD analysis of SFPC is conducted with circular tubed geometry. The effects of different fluids on thermal efficiency have been investigated in this research paper.

\section{Mathematical models and computational methodology}

For solving mathematical equations, the commercial computational fluid dynamics (CFD) code, ANSYS FLUENT ${ }^{\circ} 14.0$, using the finite-volume technique was selected in a 3-D grid system. In the CFD code, algorithm solution employed was really forceful and enables the flexibility in usages of any unstructured and structured grids in the equation.

\subsection{Numerical solution}

The turbulent flow model was taken into consideration for the calculations that are based on the given operating conditions evaluated in the equations. The $k-\varepsilon$ model was implemented for the modeling of the turbulent flow. The heat transfer in the glass cover was considered when comparing the relationship between the tube and the absorber plate. The working fluid flow was considered in these simulations. Furthermore, the heat transfer radioactivity tracing algorithm of the solar ray was applied, in the computational domain. The models were loaded with solar ray-tracing algorithm for direct illumination of energy source for predictions and that resulted in solar radiation from the incident. The heat flux was computed on the faces of the boundary that was resulted from the radiation incident. Furthermore, in the criterion of convergence, absolute residuals were normalized for all the given variables that were limited to be less than $10^{-4}$ in each cell. The upwind first-order scheme was employed for turbulent, momentum, and energy equations in the numerical solutions.

\subsection{Governing equations}

The governing equations of mass conservation, momentum, and energy in the steady-state conditions were solved in the Cartesian tensor form, shown in Table 1.

The radiative transfer equation (RTE) was quite convenient and efficient in participating media for describing the radiation phenomena due to the sum of the given contributions of all the rays crossing into the cell. The discrete ordinate (DO) model was activated and that was taken the effects of heat transfer between absorber plate and cover glass. The number of rays and their directions were selected by RTE and solved on its way

Table 1 Governing equations solved in the research work

\begin{tabular}{lll}
\hline Physical parameter & Mathematical equation & Eq. Nos. \\
\hline Mass & $\nabla \cdot(\rho \vec{v})=S_{m}$ \\
Momentum & $\nabla \cdot(\rho \vec{v})=-\nabla p+\nabla \cdot(\overline{\bar{\tau}})+\rho+\vec{F}$ \\
Energy & $\nabla \cdot(\vec{v}(\rho E+p))=-\nabla \cdot\left(\lambda_{\text {eff }} \nabla T-\sum_{j} h_{j} \vec{J}_{j}+\left(\overline{\bar{\tau}}_{\text {eff }} \cdot \vec{v}\right)\right)+S_{h}$ \\
Radiative transfer & $i_{n+1}^{\prime}=i_{n}^{\prime}\left(1-\varepsilon\left(T, x_{i}\right)\right)+i_{b}^{\prime}(T) \varepsilon\left(T, x_{i}\right)$
\end{tabular}


for each ray from boundaries to boundaries. The general basis for this method was to quantify coefficients of the absorption at the given temperature with constants. The intensities of heat radiation of cells at connections were calculated over the total spectrum [52].

$i_{n+1}^{\prime}=i_{n}^{\prime}\left(1-\varepsilon\left(T, x_{i}\right)\right)+i_{b}^{\prime}(T) \varepsilon\left(T, x_{i}\right)$

where $\varepsilon\left(T, x_{i}\right)$ represents the emissivity, $i_{b}^{\prime}=\sigma \cdot T^{4} / \pi$, is the blackbody radiation intensity in the control volume, and $\sigma$ is the Stephan-Boltzmann constant that is equal to $5.67 \times 10^{-8} \mathrm{~W} / \mathrm{m}^{2} \mathrm{~K}^{4}$.

\subsection{Computational domain}

The geometry of the SFPC was developed in the ANSYS DesignModler 14 . Half of the geometry was developed with defining symmetry planes. The developed 3D geometry of SFPC is shown in Fig. 1. The SFPC model contains one tube in which the working fluid is flowing. The fluid is inserted from the inlet zone of geometry and it exits from outlet zone. The upper plate of SFPC was considered as made up of glass. The bottom plate of the SFPC was considered as an absorbing plate. Figure 2 shows the meshed computational domain of the developed SFPC. The mesh was developed with tetrahedron cells using an uneven meshing strategy.

To study the grid convergence four grids were developed from the finest to coarse mesh density with cell sizes of $142,578,118,815,95,052$ and 71,289 . The temperature profile study was conducted with all the grids for water at medium flow rates. The temperature profiles are given in Fig. 3. It is observed from the temperature profile that the fine grids 118,815 and 142,578 shows almost similar temperature profile whereas the coarser grids show less

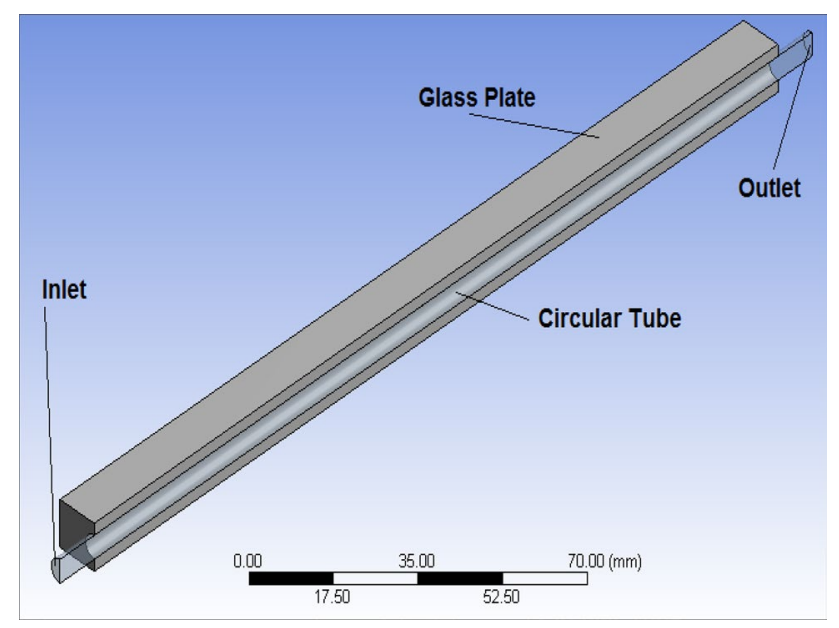

Fig. 1 3-D geometry of SFPC

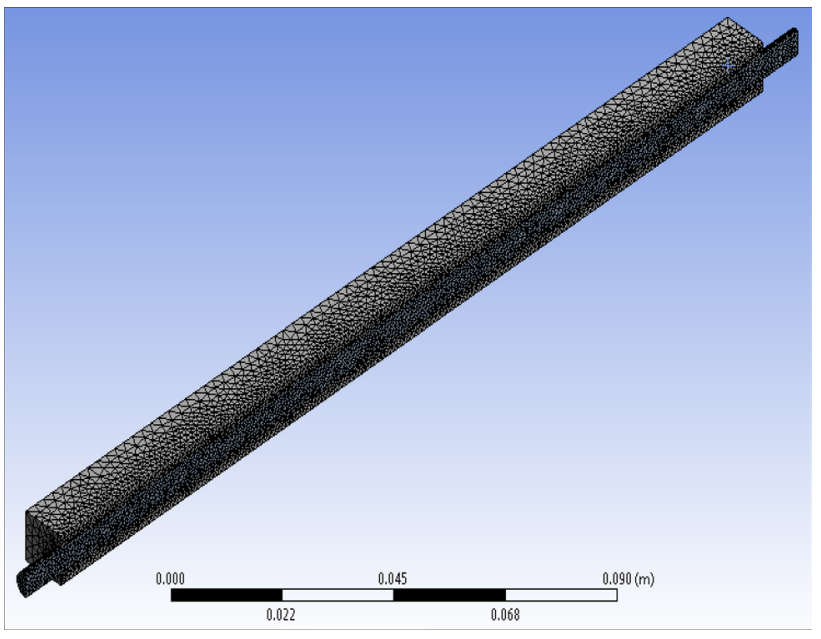

Fig. 2 Meshed structure of computational domain of SFPC

temperature. Hence the grid with mesh size 118,815 was selected for further simulations.

The minimum orthogonal quality was 0.54 . Usually, the orthogonal quality greater than 0.3 is considered good for computations. Further, the grid independence test was carried out and this grid gave optimum results.

\subsection{Assumptions, convergence criteria and boundary conditions}

Firstly, the flow of the fluid was assumed fully-developed and to be a steady flow. The heat losses were neglected in these circumstances and the flow of the fluid was assumed to be incompressible within the boundary conditions. The fluid flow directions were along the axis of the tube. The properties, such as thermo-physical, thermal conductivity,

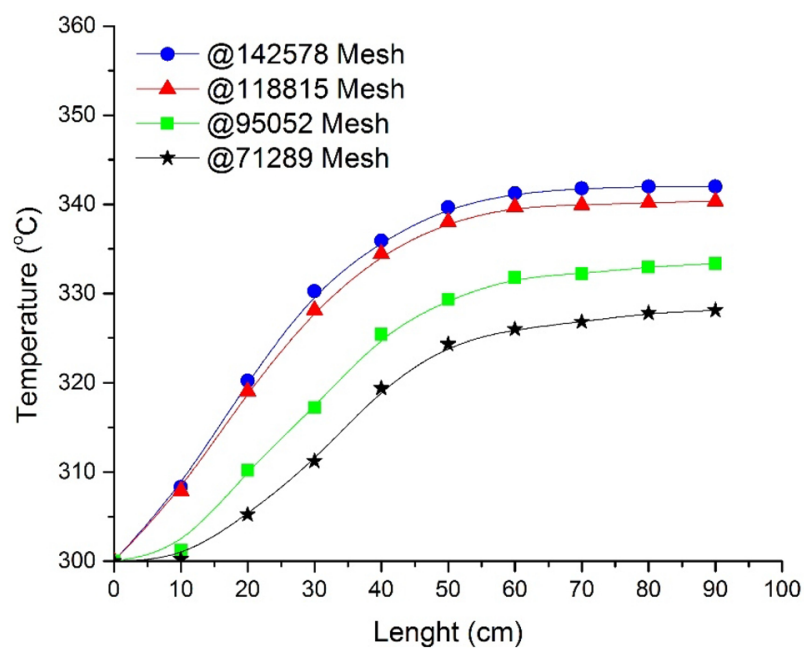

Fig. 3 Grid independence study

\section{SN Applied Sciences}


Table 2 Varying parameters of simulated cases

\begin{tabular}{llc}
\hline Case no. & Working fluid & Mass flow rate $(\mathrm{kg} / \mathrm{s})$ \\
\hline 1 & Water & $5 \times 10^{-6}$ \\
2 & Water & $8 \times 10^{-6}$ \\
3 & Water & $1.1 \times 10^{-5}$ \\
4 & Air & $5 \times 10^{-6}$ \\
5 & Air & $8 \times 10^{-6}$ \\
6 & Air & $1.1 \times 10^{-5}$ \\
\hline
\end{tabular}

temperature and density of fluids were taken into consideration. The condition of non-slip was applied, for all the wall surfaces. Thermal conditions for absorber plate were set at Radiation with external emissivity at 1 and default external radiation temperature at $300 \mathrm{~K}$. Whereas the thermal conditions for glass and other walls were set at convection with heat transfer coefficient at $2 \mathrm{~W} / \mathrm{m}^{2} \mathrm{~K}$ and default-free stream temperature at $300 \mathrm{~K}$.

The conduction of the heat for the riser tube and the absorber using the approach of shell conduction was computed. The algorithm SIMPLE between the pressure and velocity was used for solving the combinations. Such values that are used for the absorptivity of the absorber and transmissivity of glass of flat plate solar collector were 00.95 and 00.91 respectively. The solution converge when the mass, turbulent kinetic energy and momentum residuals satisfied at $10^{-3}$ and energy residuals and radiation at $10^{-5}$ were achieved. Table 2 defines the variations in the parameters in different simulated cases. A total of 6 simulations was performed, 3 were performed on the water as working fluid whereas the rest of the 3 was performed by taking air as working fluid. Both the fluids were tested at a low, medium and high mass flow rates. The boundary conditions along with absorptivity and transmissivity of absorbing plate and glass are tabulated in Table 3. The constant values of different properties of selected materials are given in Table 4.
Table 4 Fixed properties of flowing fluids

\begin{tabular}{lll}
\hline Property (unit) & \multicolumn{2}{l}{ Value for each fluid } \\
\cline { 2 - 3 } & Water & Air \\
\hline Density $\left(\mathrm{kg} / \mathrm{m}^{3}\right)$ & 998.2 & 1.225 \\
Specific heat, Cp $(\mathrm{J} / \mathrm{kg} \mathrm{K})$ & 4182 & 1006.43 \\
Thermal conductivity $(\mathrm{W} / \mathrm{m} \mathrm{K})$ & 0.6 & 0.0242 \\
Viscosity $(\mathrm{kg} / \mathrm{m} \mathrm{s})$ & 0.001003 & $1.7894 \times 10^{-5}$ \\
\hline
\end{tabular}

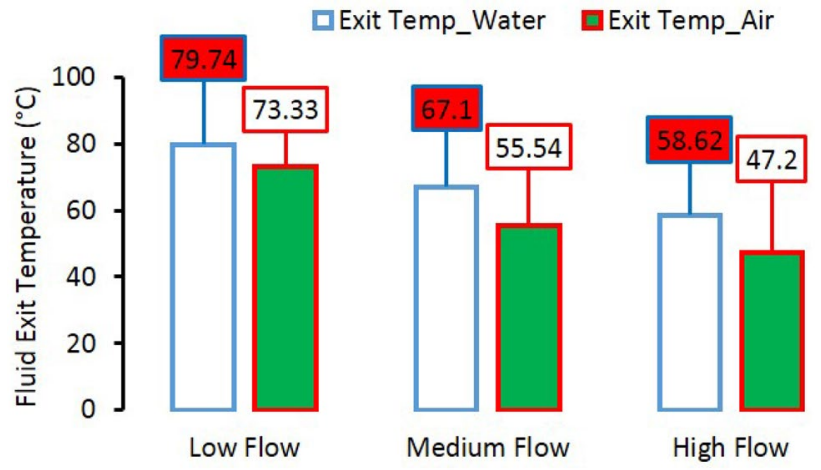

Fig. 4 Exit temperatures of fluid in all the simulated cases

\section{Results and discussion}

The solar flat plate collector (SFPC) was numerically simulated using Ansys FLUENT commercial CFD Code. The SFPC contained a single circular tube. The upper plate was considered of glass sheet whereas the bottom plate was considered as an absorber. Two working fluids were tested i.e., water and air. The inlet temperature for both the fluids was maintained at $300 \mathrm{~K}$. The Hyderabad coordinates were used to calculate the solar radiation intensity. Both water and air were inserted with 3 different flow rates termed as low flow, medium flow, and high flow. The detailed results are discussed in the subsequent paragraphs.
Table 3 Fixed properties of absorbing and glass plates

\begin{tabular}{llll}
\hline Plate & Boundary condition type & Absorptivity & Transmissivity \\
\hline Absorbing plate & Opaque & Direct visible: 0.8 & - \\
& & Direct IR: 0.8 & \\
Glass plate & Semi-transparent & Direct visible: 0.1 & Direct visible: 0.8 \\
& & Direct IR: 0.1 & Direct IR: 0.8 \\
& & Diffuse hemispherical: 0.1 & Diffuse Hemispherical: 0.8 \\
\hline
\end{tabular}




\subsection{Exit average temperature}

In all simulations an increase in the exit temperature was observed for both the fluids as compared to inlet temperature due to solar radiation. Figure 4 shows the average exit temperatures for both the working fluids at three different flowing conditions. The water at low flowrate $\left(5 \times 10^{-6}\right.$ $\mathrm{kg} / \mathrm{s}$ ) leaving the tube at $79.74^{\circ} \mathrm{C}$ which is the highest gain in temperature for all the cases. The probable reason is higher thermal conductivity and increased residence time due to low flow rate [10]. The temperature of water at a medium flow rate $\left(8 \times 10^{-6} \mathrm{~kg} / \mathrm{s}\right)$ increased up to $67.1^{\circ} \mathrm{C}$ from the ambient condition. This is further decreased up to $58.62^{\circ} \mathrm{C}$ at a high flow rate $\left(1.1 \times 10^{-5} \mathrm{~kg} / \mathrm{s}\right)$ due to very low residence time. The temperatures of air could not increase as compared to water temperatures due to low thermal conductivity. Its maximum temperature reached up to $73.33^{\circ} \mathrm{C}$ at a low flow rate, which is decreased up to $55.54{ }^{\circ} \mathrm{C}$ at the medium flow rate and further decreased up to $47.2^{\circ} \mathrm{C}$ at a high flow rate. So conclusively it was observed that the performance of SFPC decreased in terms of decreased average outlet temperate of working fluid with an increase in fluid flow [31]. Another important observation is that the difference between water and air temperatures at a low flow rate is small whereas it is wider as the fluid flow increases.
Fig. 5 Contours of temperatures for simulated cases with water as working fluid
Fig. 6 Contours of temperatures for simulated cases with air as working fluid
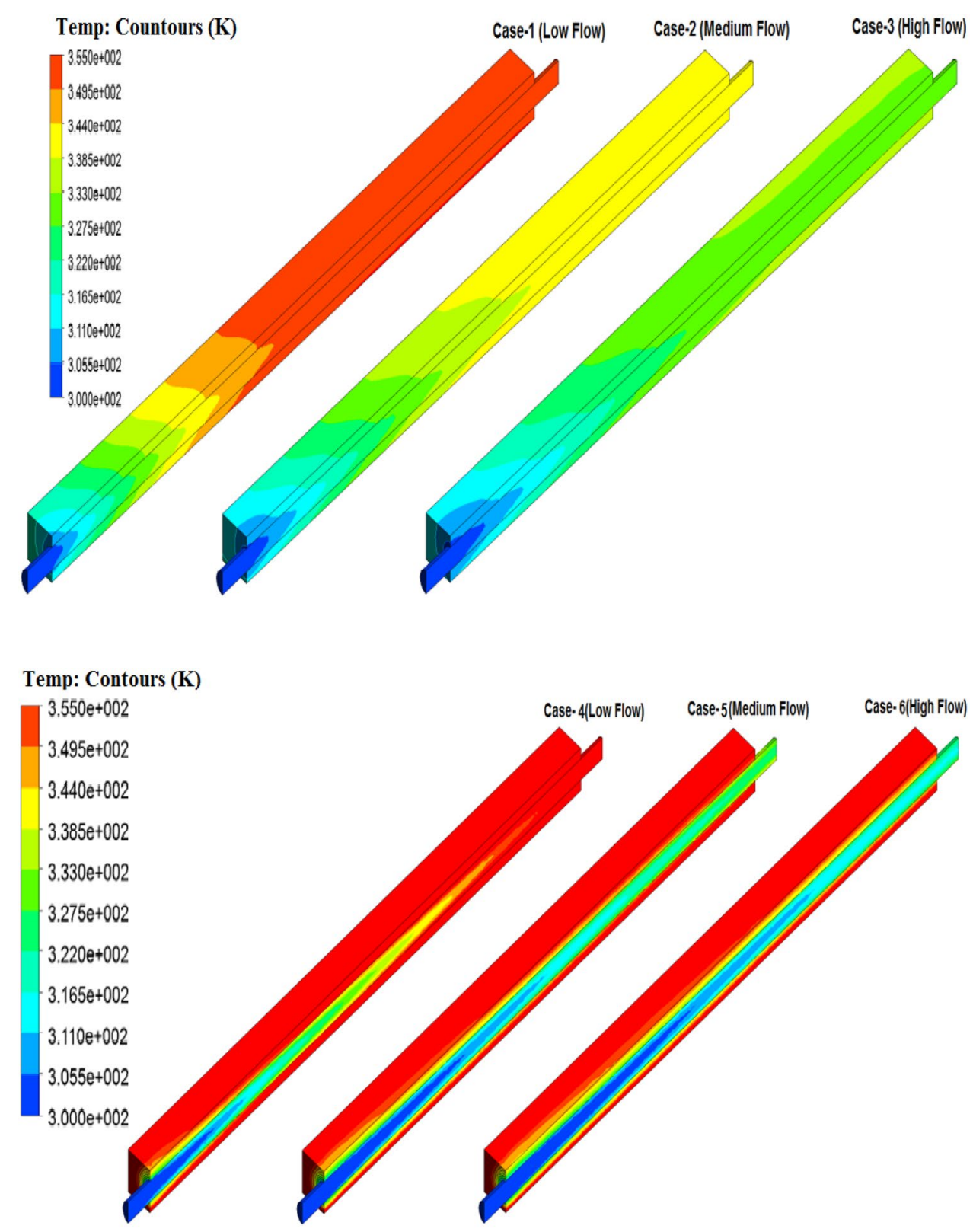


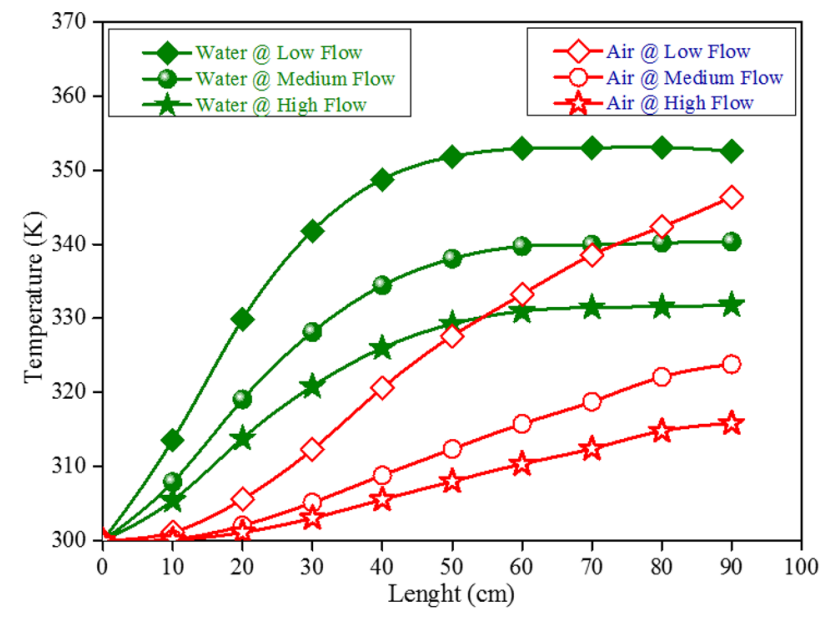

Fig. 7 Temperature behavior at different length

\subsection{Temperature contours}

In any CFD analysis, the contours show the rendered solution field within the computational domain. The temperature contours of all six simulated cases are shown in Figs. 5, 6 and 7. Whereas Fig. 5 shows the temperature contours of three cases with water as working fluids calculated at a low, medium and high flow rate of water. Figure 6 shows a similar contour for air as the working fluid. In all the contours it was observed that the fluid either water or air enters at the same ambient temperature i.e., $300 \mathrm{~K}\left(27^{\circ} \mathrm{C}\right)$ in all the cases. This is visualized by a red color. The temperature of entering fluid is starting raising once it enters in the SFPC chamber [27]. One thing should be notable here that the chamber is filled with stationary water when water is used as working fluid in the circular tube (Fig. 5) whereas chamber environment is taken stationary when the air is used as working fluid in the circular tube (Fig. 6). A uniform increase in temperature is observed in Fig. 5 for both the tube fluid as well as the chamber fluid. But with air case (Fig. 6), the air encapsulated in the chamber got high temperature but it could not transfer its maximum temperature to the flowing air in tube side due to low heat transfer rates. This is because air has low-density and possesses less thermal conductivity as compared to water [45].

\subsection{Temperature profile}

The temperature profiles for both working fluids are developed at central line of tube from all cases, as shown in Fig. 7. The blue lines with filled markers points are for water fluid, whereas the red lines with empty marker points are for air fluid. It is observed from Fig. 5 that water gets hotter earlier as compared to air along the tube length. The

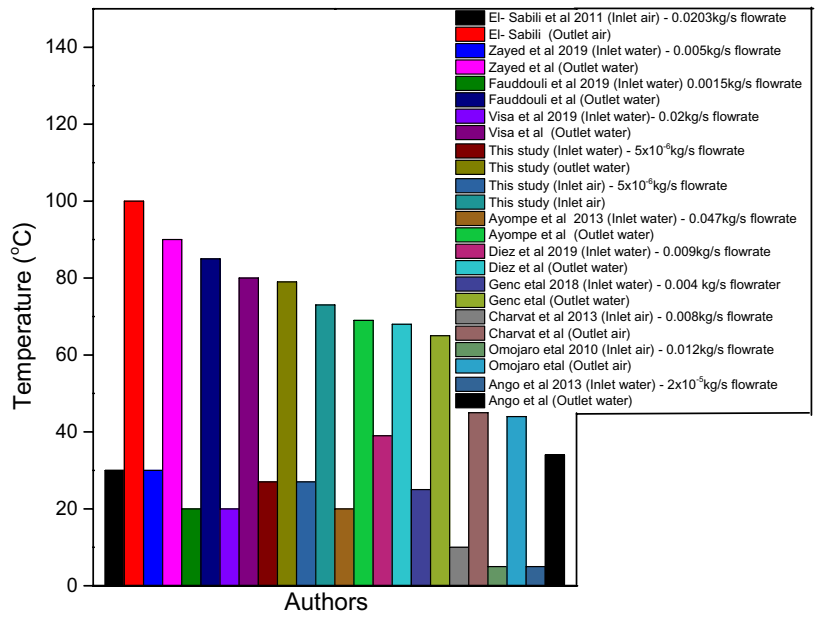

Fig. 8 Comparison of results with published literature

temperature of the water gets its peak at the mid-length of the tube and then becomes constant. Contrary to this, air temperature increases slowly and almost the trend is increasing up to the exit point. This indicates that the length of the tube is enough for water fluid but it is a little shorter for air as working fluid. The decrease in the slope of the curve with increasing flow rate is an important observation in Fig. 7. This clearly indicates that heat transfer rate with a low flow rate is higher [29] whereas high fluid flow decreases the overall heat transfer coefficient for the SFPC [36].

\subsection{Comparison of results}

The comparative study was done with published literature regarding the efficiency of the solar plate collector. Both working fluids water and air were compared with the studies conducted by other researchers on solar flat plate collectors using water and air as working fluids. A variation was observed in the results in some of the studies that are due to the variations in the inlet temperature of the working fluid. Moreover the flow rate of the working fluids was not same for the studies investigated for comparison. Besides that various researchers used different nanofluids for the efficiency improvement of solar flat plate collectors. The geometrical configuration was also different as compared to the research done by other researchers. Figure 8 shows the comparison of results with the literature $[8,14$, $16,18,19,21,24,42,54,58]$.

\subsection{Numerical studies on SFPC}

Numerous researchers have worked on the CFD simulation through the application of commercial simulation tools in order to understand the behavior of solar collectors. A 
research done by Fan et al. [22] used Fluent $6.1^{\circ}$ for the analysis of the practical data collected during the outdoor test. They compared the outdoor results collected during their experimental study with the results gathered using the CFD software. In case of high flow rates the experimental and simulated results were in good agreement however at low flowrate there were few discrepancies in results. These discrepancies may be due to the oversimplification of the collector particularly inside the air gap of the panel. The researchers [40] performed the investigation using different configuration of inside flat plate integrated collector solar water heater systems. The inside flat plate integrated collector solar water heater system was configured having single and double rows inside it. The diameter of both inside tubes were of different size. The steady-state 3D CFD approach was used to estimate the thermal performance of the system. As per findings double row design is not suitable due to high cost and high power requirement during pumping of fluid. The double row configuration had no additional benefit as compared to single row. The researchers [24] performed transient numerical simulations on flat plate solar collectors. In their research study nanofluids were used to increase the energy harvesting potential. The efficiency of solar flat plate collectors was investigated by maintaining different mass flow rates of water and varying volumetric concentrations of nanofluids $\mathrm{Al}_{2} \mathrm{O}_{3} 1 \%, 2 \%$, and $3 \%$ respectively. As per their research, best performance of solar flat plate collectors was achieved at the water flowrate of $0.004 \mathrm{~kg} / \mathrm{s}$ and at the volumetric concentration of nanofluids $3 \%$. The nanofluids helped in increasing efficiency of solar flat plate collector at lower mass flow rates of working fluid.

\subsection{Challenges for efficient application of SFPC}

Numerous challenges are yet to be addressed for the efficient utilization of solar flat plate collector. The most critical challenges include the effect of dust settlement on the surface of solar flat collector and its estimation of effect on efficiency of solar collectors. The settlement of dust particles on solar installations misleads the experimental results. Therefore the estimation of the level of pollution and its composition is very important before performing the experimental study of solar installations. The high polluted areas affect the efficiency of solar installing at larger scale. Therefore simulation studies need to be carried out in order to understand effect of polluted areas on solar installations. Another challenge that needs to be addressed through the experimental and simulation studies is the effect of wind movements such as speed and direction of wind is to be estimated in high wind areas. The speed and direction of wind also increase the dust level settlement on solar installations. The size, geometry deposition behavior, biological and electrochemical behavior of dust needs to be assessed numerically and experimentally. The effect of working fluid such as dissolved salts in the water deposit on the glass surface affect the performance of the installed solar system. Therefore above-mentioned parameters are yet the challenges that need further research to understand the true performance of the solar installations.

\section{Conclusion}

The solar flat plate collector (SFPC) performance was evaluated through CFD simulations. It was observed that water gave higher efficiency due to high density and thermal conductivity. The simulation results gathered revealed that the temperature of water and air was raised up to $79^{\circ} \mathrm{C}$ and $73^{\circ} \mathrm{C}$. It was observed from the temperature profile that the fine grids 118,815 and 142,578 show almost similar temperature profile as compared to coarser grids. The minimum orthogonal quality was 0.54 . Usually, the orthogonal quality greater than 0.3 is considered good for computations. The maximum exit temperature was achieved $79.74{ }^{\circ} \mathrm{C}$ for water at its lowest flow rate i.e., $5 \times 10^{-6} \mathrm{~kg} / \mathrm{s}$ whereas minimum temperature of $47.2^{\circ} \mathrm{C}$ was achieved with air-fluid at the highest flow rate i.e., $1.1 \times 10^{-5} \mathrm{~kg} / \mathrm{s}$. The water fluid presented good performance over the air for SFPC due to the high density and thermal conductivity. The gradual increase for both stationary and flowing water was observed whereas in case of air, the stationary air got hotter but could not transfer heat properly due to low density. Increased slopes of temperature rise were observed for water fluid whereas air temperature rise was slower. Overall it was concluded that the SFPC has shown excellent performance with water fluid. Proper design, transient studies and increased number of tubes could be the future work from this research.

Acknowledgements The authors are highly grateful to Chemical Engineering Department Mehran University of Engineering and Technology Jamshoro for providing mandatory facilities required for the accomplishment of this research work.

\section{Compliance with ethical standards}

Conflict of interest On behalf of all authors, the corresponding author states that there is no conflict of interest.

\section{References}

1. Akademia Baru P, Muhammad M, Che Sidik NA et al (2016) Thermal performance of thermosyphon evacuated tube solar collector using $\mathrm{TiO}_{2}$ /water nanofluid. J Adv Res Fluid Mech Therm Sci 20:12-29 
2. Al-Waeli AHA, Sopian K, Chaichan MT et al (2017) An experimental investigation of $\mathrm{SiC}$ nanofluid as a base-fluid for a photovoltaic thermal PV/T system. Energy Convers Manag 142:547-558

3. Ali $\mathrm{HM}$, Ali $\mathrm{H}$, Liaquat $\mathrm{H}$ et al (2015) Experimental investigation of convective heat transfer augmentation for car radiator using ZnO-water nanofluids. Energy 84:317-324

4. Ali HM, Arshad W (2015) Thermal performance investigation of staggered and inline pin fin heat sinks using water based rutile and anatase $\mathrm{TiO}_{2}$ nanofluids. Energy Convers Manag 106:793-803

5. Ali HM, Arshad W (2017) Effect of channel angle of pin-fin heat sink on heat transfer performance using water based graphene nanoplatelets nanofluids. Int J Heat Mass Transf 106:465-472

6. Ali M, Khan SA, Sheikh NA et al (2017) Performance analysis of a low capacity solar tower water heating system in climate of Pakistan. Energy Build 143:84-99

7. Arshad W, Ali HM (2017) Graphene nanoplatelets nanofluids thermal and hydrodynamic performance on integral fin heat sink. Int J Heat Mass Transf 107:995-1001

8. Ayompe LM, Duffy A (2013) Analysis of the thermal performance of a solar water heating system with flat plate collectors in a temperate climate. Appl Therm Eng 58:447-454

9. Bagheri N, Nazilla T, Javadikia H (2015) Development and evaluation of an adaptive neuro fuzzy interface models to predict performance of a solar dryer. Agric Eng Int CIGR J 17:112-121

10. Bakry Al, El-Samadony YAF, El-Agouz SA et al (2018) Performance of the one-ended evacuated tubes as medium temperature solar air heaters at low flow rates. Sustain Energy Technol Assess 30:174-182

11. Boukelia TE, Arslan O, Mecibah MS (2016) ANN-based optimization of a parabolic trough solar thermal power plant. Appl Therm Eng 107:1210-1218

12. Brezzi F, Russo A (1994) Choosing bubbles for advection-diffusion problems. Math Models Methods Appl Sci 04:571-587

13. Chang H, Duan C, Wen K et al (2015) Modeling study on the thermal performance of a modified cavity receiver with glass window and secondary reflector. Energy Convers Manag 106:1362-1369

14. Charvat $P$, Klimes L, Pech O (2013) Experimental and numerical study into solar air collectors with integrated latent heat thermal storage. In: Central Europe towards sustainable building. Lowtech and high-tech materials and technologies for sustainable buildings, $\mathrm{pp} 1-4$

15. Crisostomo F, Hjerrild N, Mesgari S et al (2017) A hybrid PV/T collector using spectrally selective absorbing nanofluids. Appl Energy 193:1-14

16. Diez FJ, Navas-Gracia LM, Martínez-Rodríguez A et al (2019) Modelling of a flat-plate solar collector using artificial neural networks for different working fluid (water) flow rates. Sol Energy 188:1320-1331

17. Dikmen E, Ayaz M, Ezen HH et al (2014) Estimation and optimization of thermal performance of evacuated tube solar collector system. Heat Mass Transf 50:711-719

18. Do Ango ACM, Médale $M$, Abid C (2013) Optimization of the design of a polymer flat plate solar collector. Sol Energy 87:64-75

19. El-Sebaii AA, Aboul-Enein S, Ramadan MRI et al (2011) Thermal performance investigation of double pass-finned plate solar air heater. Appl Energy 88:1727-1739

20. Elum ZA, Momodu AS (2017) Climate change mitigation and renewable energy for sustainable development in Nigeria: a discourse approach. Renew Sustain Energy Rev 76:72-80

21. Faddouli A, Labrim H, Fadili S et al (2019) Numerical analysis and performance investigation of new hybrid system integrating concentrated solar flat plate collector with a thermoelectric generator system. Renew Energy 147:2077-2099
22. Fan J, Shah LJ, Furbo S (2007) Flow distribution in a solar collector panel with horizontally inclined absorber strips. Sol Energy 81:1501-1511

23. FS-UNEP B (2016) Global trends in renewable energy investment 2016. Frankfurt School-UNEP Centre and Bloomberg New Energy Finance

24. Genc AM, Ezan MA, Turgut A (2018) Thermal performance of a nanofluid-based flat plate solar collector: A transient numerical study. Appl Therm Eng 130:395-407

25. Hamdan M, Abdelhafez E, Hamdan A et al (2014) Heat transfer analysis of a flat-plate solar air collector by using artificial neural network. J Infrastruct Syst 22:1-7

26. Hassani S, Saidur R, Mekhilef S et al (2016) Environmental and exergy benefit of nanofluid-based hybrid PV/T systems. Energy Convers Manag 123:431-444

27. Helvaci U, Khan Z (2015) Mathematical modelling and simulation of multiphase flow in a flat plate solar energy collector

28. Hjerrild NE, Mesgari S, Crisostomo F et al (2016) Hybrid PV/T enhancement using selectively absorbing $\mathrm{Ag}-\mathrm{SiO}_{2} /$ carbon nanofluids. Sol Energy Mater Sol Cells 147:281-287

29. Islam MP, Morimoto T (2018) Advances in low to medium temperature non-concentrating solar thermal technology. Renew Sustain Energy Rev 82:2066-2093

30. Jafarkazemi F, Ahmadifard E (2013) Energetic and exergetic evaluation of flat plate solar collectors. Renew Energy 56:55-63

31. Jothirathinam S, Nagarajan $P$, Wongwises $S$ et al (2018) Experimental study on the thermal performance and heat transfer characteristics of solar parabolic trough collector using $\mathrm{Al}_{2} \mathrm{O}_{3}$ nanofluids

32. Kalogirou SA (2006) Prediction of flat-plate collector performance parameters using artificial neural networks. Sol Energy $80: 248-259$

33. Kalogirou SA, Panteliou S, Dentsoras A (1999) Modeling of solar domestic water heating systems using artificial neural networks. Sol Energy 65:335-342

34. Karami N, Rahimi M (2014) Heat transfer enhancement in a PV cell using Boehmite nanofluid. Energy Convers Manag 86:275-285

35. Khan MMA, Ibrahim NI, Mahbubul IM et al (2018) Evaluation of solar collector designs with integrated latent heat thermal energy storage: a review. Sol Energy 166:334-350

36. Khanmohammadi S, Saadat-Targhi M (2019) Performance enhancement of an integrated system with solar flat plate collector for hydrogen production using waste heat recovery. Energy 171:1066-1076

37. Manjunath M, Karanth VK, Sharma YN (2011) Three dimensional numerical analysis of conjugate heat transfer for enhancement of thermal performance using finned tubes in an economical unglazed solar flat plate collector. In: Proceedings of the world congress on engineering, vol III. London, UK

38. Manjunath M, Karanth VK, Sharma YN (2012) A comparative CFD study on solar dimple plate collector with flat plate collector to augment the thermal performance. World Acad Sci Eng Technol 2012:969-975

39. Mohammad Zadeh P, Sokhansefat T, Kasaeian AB et al (2015) Hybrid optimization algorithm for thermal analysis in a solar parabolic trough collector based on nanofluid. Energy 82:857-864

40. Mossad R, Al-Khaffajy M (2012) Investigating two configurations of a heat exchanger in an Indirect Heating Integrated Collector Storage Solar Water Heater System (IHICSSWHS). Renew Energy Power Qual J 10:1-6

41. Mussard M (2017) Solar energy under cold climatic conditions: a review. Renew Sustain Energy Rev 74:733-745 
42. Omojaro AP, Aldabbagh LBY (2010) Experimental performance of single and double pass solar air heater with fins and steel wire mesh as absorber. Appl Energy 87:3759-3765

43. Petroleum B (2013) BP statistical review of world energy June 2013. British Petroleum, London

44. Ranjbar-Mohammadi M, Prabhakaran MP, Bahrami SH et al (2016) Gum tragacanth/poly(l-lactic acid) nanofibrous scaffolds for application in regeneration of peripheral nerve damage. Carbohyd Polym 140:104-112

45. Sadeghi G, Safarzadeh H, Bahiraei M et al (2019) Comparative study of air and argon gases between cover and absorber coil in a cylindrical solar water heater: an experimental study. Renew Energy 135:426-436

46. Sajid MU, Ali HM (2018) Thermal conductivity of hybrid nanofluids: a critical review. Int J Heat Mass Transf 126:211-234

47. Sardarabadi M, Passandideh-Fard M, Zeinali Heris S (2014) Experimental investigation of the effects of silica/water nanofluid on PV/T (photovoltaic thermal units). Energy 66:264-272

48. Shahmaleki P, Mahzoon M (2010) GA modeling and ANFIS control design for a solar power plant. In: Proceedings of the 2010 American Control Conference, pp 3530-3535

49. Struckmann F (2008) Analysis of a flat-plate solar collector. Heat and Mass Transport, Project Report, 2008MVK160

50. Taylor RA, Otanicar T, Rosengarten G (2012) Nanofluid-based optical filter optimization for PV/T systems. Light Sci Appl 1:e34-e34

51. Tomy AM, Ahammed N, Subathra MSP et al (2016) Analysing the performance of a flat plate solar collector with silver/water nanofluid using artificial neural network. Procedia Comput Sci 93:33-40

52. Versteeg HK, Malalasekera W (2007) An introduction to computational fluid dynamics: the finite volume method. Pearson Education, London
53. Viral R, Khatod DK (2012) Optimal planning of distributed generation systems in distribution system: a review. Renew Sustain Energy Rev 16:5146-5165

54. Visa I, Moldovan M, Duta A (2019) Novel triangle flat plate solar thermal collector for facades integration. Renew Energy 143:252-262

55. Voyant C, Notton G, Kalogirou S et al (2017) Machine learning methods for solar radiation forecasting: a review. Renew Energy 105:569-582

56. Wallerand AS, Selviaridis A, Ashouri A et al (2016) Targeting optimal design and operation of solar heated industrial processes: a MILP formulation. Energy Procedia 91:668-680

57. Yang Z, Zhang Y, Dong Q et al (2018) Maximum power output and parametric choice criteria of a thermophotovoltaic cell driven by automobile exhaust. Renew Energy 121:28-35

58. Zayed ME, Zhao J, Elsheikh AH et al (2019) Performance augmentation of flat plate solar water collector using phase change materials and nanocomposite phase change materials: a review. Process Saf Environ Prot 128:135-157

59. Zima W, Dziewa P (2010) Mathematical modelling of heat transfer in liquid flat-plate solar collector tubes. Arch Thermodyn 31:45-62

60. Zima W, Dziewa P (2011) Modelling of liquid flat-plate solar collector operation in transient states. Proc Inst Mech Eng Part A: J Power Energy 225:53-62

Publisher's Note Springer Nature remains neutral with regard to jurisdictional claims in published maps and institutional affiliations. 